\title{
Heuristic Storage System Sizing for Optimal Operation of Electric Vehicles Powered by Photovoltaic Charging Station
}

\author{
Erik Blasius, ${ }^{1}$ Erik Federau, ${ }^{1}$ Przemyslaw Janik, ${ }^{2}$ and Zbigniew Leonowicz ${ }^{2}$ \\ ${ }^{1}$ Faculty of Mechanical, Electrical, and Industrial Engineering, Brandenburg University of Technology Cottbus-Senftenberg, \\ Siemens-Halske-Ring 13, 03046 Cottbus, Germany \\ ${ }^{2}$ Faculty of Electrical Engineering, Wroclaw University of Science and Technology, Wybrzeże Wyspianskiego 27, \\ 50-370 Wroclaw, Poland \\ Correspondence should be addressed to Zbigniew Leonowicz; zbigniew.leonowicz@pwr.edu.pl
}

Received 28 March 2016; Accepted 28 June 2016

Academic Editor: Mark van Der Auweraer

Copyright (C) 2016 Erik Blasius et al. This is an open access article distributed under the Creative Commons Attribution License, which permits unrestricted use, distribution, and reproduction in any medium, provided the original work is properly cited.

\begin{abstract}
This paper discusses the utilisation of PV systems for electric vehicles charging for transportation requirements of smart cities. The gap between PV power output and vehicles charging demand is highly variable. Therefore, there is a need for additional support from a public distribution grid or a storage device in order to handle the residual power. Long term measurement data retrieved from a charging station for 15 vehicles equipped with a PV system were used in the research. Low and high irradiation seasons influenced the PV output. The charging demand of electric vehicles varied over the course of a year and was correlated to weather conditions. Therefore, the sizing and performance of a supportive storage device should be evaluated in a statistical manner using long period observations.
\end{abstract}

\section{Introduction}

Emission-free mobility is indispensable part of the national sustainable development strategy supported by authorities [1]. Therefore the National Platform of Electric Mobility under participation of representatives of science, industry, politics, local authority districts, and consumers developed proposals to reach the national goals in Germany [2]. Accordingly, numerous projects and research activities are developed with electric vehicles interacting with power distribution grids. Charging stations for electric vehicles are connecting points between public grid and electric vehicles and are often understood as additional, highly variable loads deteriorating the hosting capacity of the network and overall performance of the existing grids [3]. For this reason, technical framework and management systems are needed to reduce the negative effects of high penetrations of electric vehicles in the public grid [4]. Starting at penetration levels of $20 \%$ conventional public grids can reach inadmissible operation states [5]. Furthermore, unavoidable power losses in the distribution and the common use of energy from fossil fuels for charging marginalise the zero emission effect of an electric vehicle [6].

Therefore, charging stations fed by locally installed photovoltaic systems are suggested as optimal solution for electric mobility [7]. Moreover, a rising proportion of electric vehicles can improve the integration of renewable energies and decrease $\mathrm{CO}_{2}$ emissions [8]. But there must be a close coordination between load profiles and fluctuating energy production, to reach the intelligent integration of components such electric vehicles and photovoltaic systems [9]. The advantages coming from the combination of both systems, for the society in general and the prosumer, lead to emissionfree mobility and cost efficiency towards the smart cities concept in the future [10]. Unfortunately, the appealing idea of a sun-powered charging station for electric vehicles was reduced in many cases to a marketing slogan. The use of a small PV system installed by a prosumer for vehicle charging can be justified only in terms of advantages averaged over long period of time [11]. Statistically, a certain part of energy consumed by an electric car over such a long period of time, for example, one year, can be covered by the PV system output 
[12]. The idea of green mobility explained in this way seems to be welcomed by the public opinion. It helps in the market placement of new products and stimulates the ecological awareness.

However, the performance of a small PV installation used for vehicle charging is definitely not green when considering shorter period of time: a day, one hour, and one second. The utilisation of such combined systems is then disputable. There is a highly variable gap between PV system power output and vehicles dumb charging demand. The term dumb means that the electric vehicle is charged with maximum allowed power immediately from the moment, when connected to the grid [13]. The public distribution grid is heavily loaded to absorb the PV overproduction or to deliver energy to vehicles by negligible PV output. The grid hosting capacity decreases; the transmission losses increase.

Utilisation of storage units and adequate sizing of the PV system are appropriate straightforward methods for the reduction of power flows in the distribution grids [14] and discussed in papers $[15,16]$. With the continuous increase of these components and, in addition to it, the uncontrolled charging of electric vehicles, there is an urgent requirement for a management system that controls all participants of a selected part of the grid [17]. The residual power and residual energy are two relevant parameters for the description of concurrent power generation and charging demand [18].

The assessment of measured charging characteristics and PV power outputs is the starting point in the approach to procedure proposal aimed at optimal matching and sizing of system components. An optimal combination of PV generation, charging stations, and storage should contribute to emission-free mobility.

The charging of vehicles by the PV system has a priority. Consequently, there are various possibilities to approach the discrepancy between generation and demand:

(i) evaluation of a quality factor for the assessment of residual power in a statistical sense;

(ii) reduction of residual power through over-dimensioning of the PV system;

(iii) integration of an storage unit into the charging system with regard to optimal sizing in statistical sense.

All the approaches will be presented in this paper in detailed manner. Various time periods have been studied separately: a day and a week each at spring and winter.

\section{Solar Energy Research Field}

2.1. Basic Components and Functions of SERF. The charging of electric vehicles using solar energy was assessed over a long period of time (exceeding one year) in the microgrid (MG) called Solar Energy Research Field "SERF" located at the Brandenburg Technical University in Cottbus, Germany. A schematic diagram of the SERF system is shown in Figure 1. A photovoltaic generation unit (PV) and a charging stations pool (CSP) are the leading components.
The switchbox (Figure 1) is a central element governing the power flow in the system. The 530 polycrystalline PV panels with $116 \mathrm{~kW}_{\text {peak }}$ are mounted on a roof. The momentary power output of the PV system is influenced by the positon of the sun, duration of the day, season, shadowing pattern caused by weather conditions, and so forth. Generally, the momentary power output can be predicted with very low accuracy. All this factors influence the availability of power for charging but also, in an indirect manner, the behaviour of the electric car drivers, that is, the power demand.

The power demand is a sum of all connected electric vehicles. There are 15 charging stations in the pool. The maximal charging power of one station is $22 \mathrm{~kW}$. The power rating governed by the switchbox is $110 \mathrm{~kW}$. Therefore, it is not possible that all charging stations could deliver the maximal power at the same time. The control is provided by an energy management system of the whole CSP. The loading power curve is a function of the arrival time of individual vehicles and corresponding charging demands.

\subsection{Location of Measurement Instruments and Measured} Data. Consistent data measurement is a prerequisite for adequate data assessment and data analysis. All data were captured in homogenous measurement units provided by the same manufacturer. An average value over one second of active power was stored in a database. One-second averaging was suitable for the covering of rapid changes, especially in the PV system power output. Every charging station was equipped with a measurement unit. Separately, the power of the whole CSP was recorded. A measurement unit was also located at the output of the PV system. The onesecond approach resulted in high data flow to be managed by the processing system, requiring adequate and robust data transfer protocol and high data transfer speeds. The assessment of long period measurements with one-second resolution is a relatively time consuming procedure. The resolution to be used is a trade-off between accuracy and required computation speed and memory requirements.

\section{Charging Station as an Interface Point between Electric Vehicle and the Microgrid}

The charging station is a connection between the electric vehicle and the MG. The user can select between one-phase charging over Schu-Ko power socket (mode 2 charging) or three-phase charging over type 2 power socket according to EN 62196-2 (mode 3 charging) [19]. The most important elements of the charging stations are depicted in Figure 2.

Every charging station is equipped with an EthernetSwitch enabling the communication with other components to keep data transfer at possibly low level. A four-quadrant measurement unit connected to the Ethernet-Switch captures currents, voltages, and power. All one-second data are transferred through programmable logic controller (PLC) to the energy management system and then archived. Moreover, a charge controller as part of the electric vehicle supply equipment (EVSE) was installed to provide mode 3 charging according to EN 61851-1 [20]. This charging control unit 


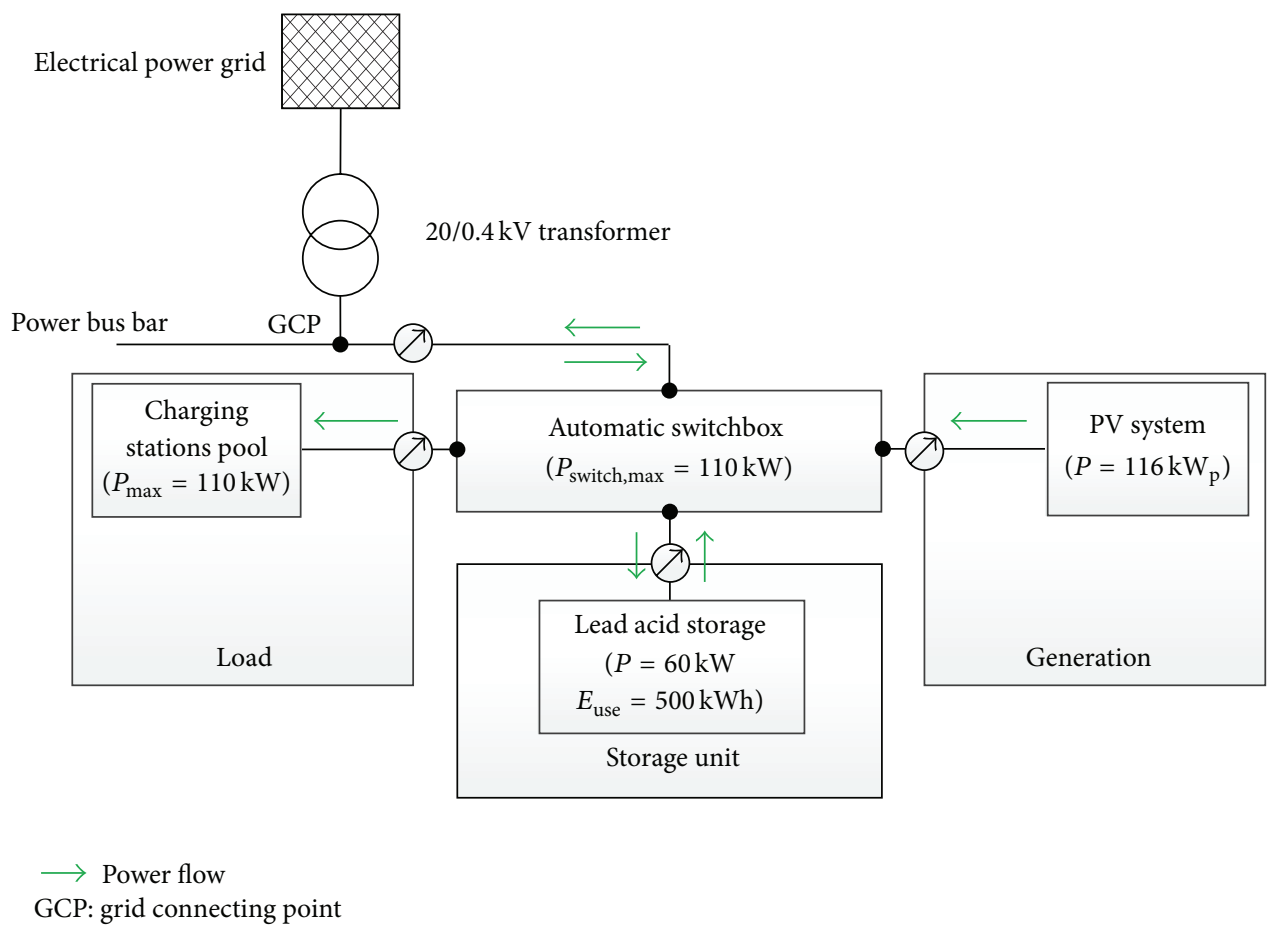

(a)

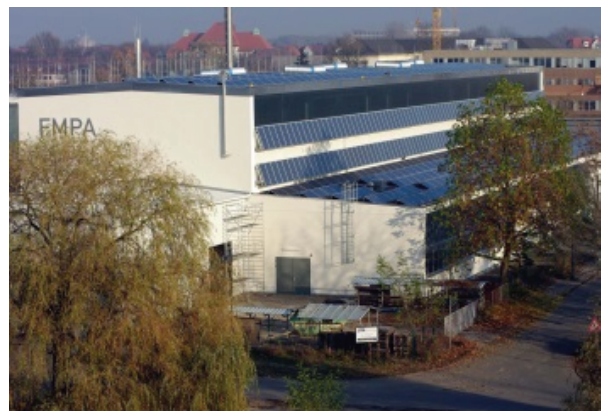

(b)

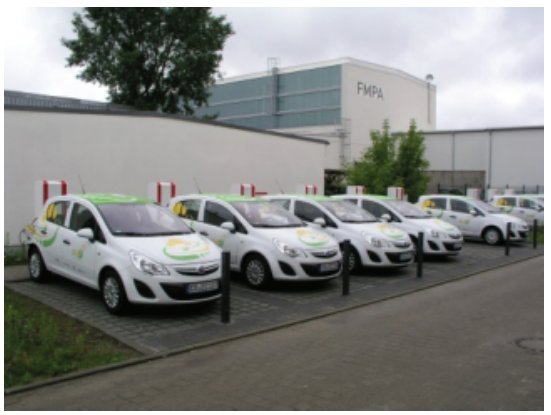

(c)

FIgURE 1: The Microgrid installation “SERF." (a) Schematic representation. (b) Overview of the PV panels' arrangement. (c) Charging stations pool.

controls the maximal charging current and the correct feeder connection, among others. Also the maximal charging current can be controlled over a pulse-width modulated signal. The battery management system (BMS) in the connected electric vehicle has a priority in the settling of the required current value.

The PLC calculates the maximal allowed charging current for a vehicle, which is not delivered by EVSE or BMS. This value is indispensable for the power management of the whole CSP. The minimum and maximum values of the charging current are needed for the charging control process. The PLC manages selected charging constraints and collects data of the local feeder parameters. Autonomous procedures guarantee power delivery in a case of a communication breakdown.

The electric vehicle and the included battery management system are a black box, with externally determined parameters which are accessible only in the terms given in EN 61851-1.
The energy management system is the central control unit governing the whole CSP. The 15 charging stations communicate over the respective PLCs. The energy management system computes the maximal allowed total charging current of the whole CSP, which is evenly distributed over all vehicles working with level 3 charging.

The drivers of all electric vehicles are commuters and worker of the university. For that reason there is a significant characteristic arrival and departure times which varies strongly being related to the individual working hours. Thus the CSP has the overall characteristics of a commuter car park in a semipublic area. The participating electric vehicles itself are all of the same model, the German E-Car Cetos.

\section{Charging Process}

The charging stations support mode 2 and mode 3 charging. The individual characteristics of both options with 


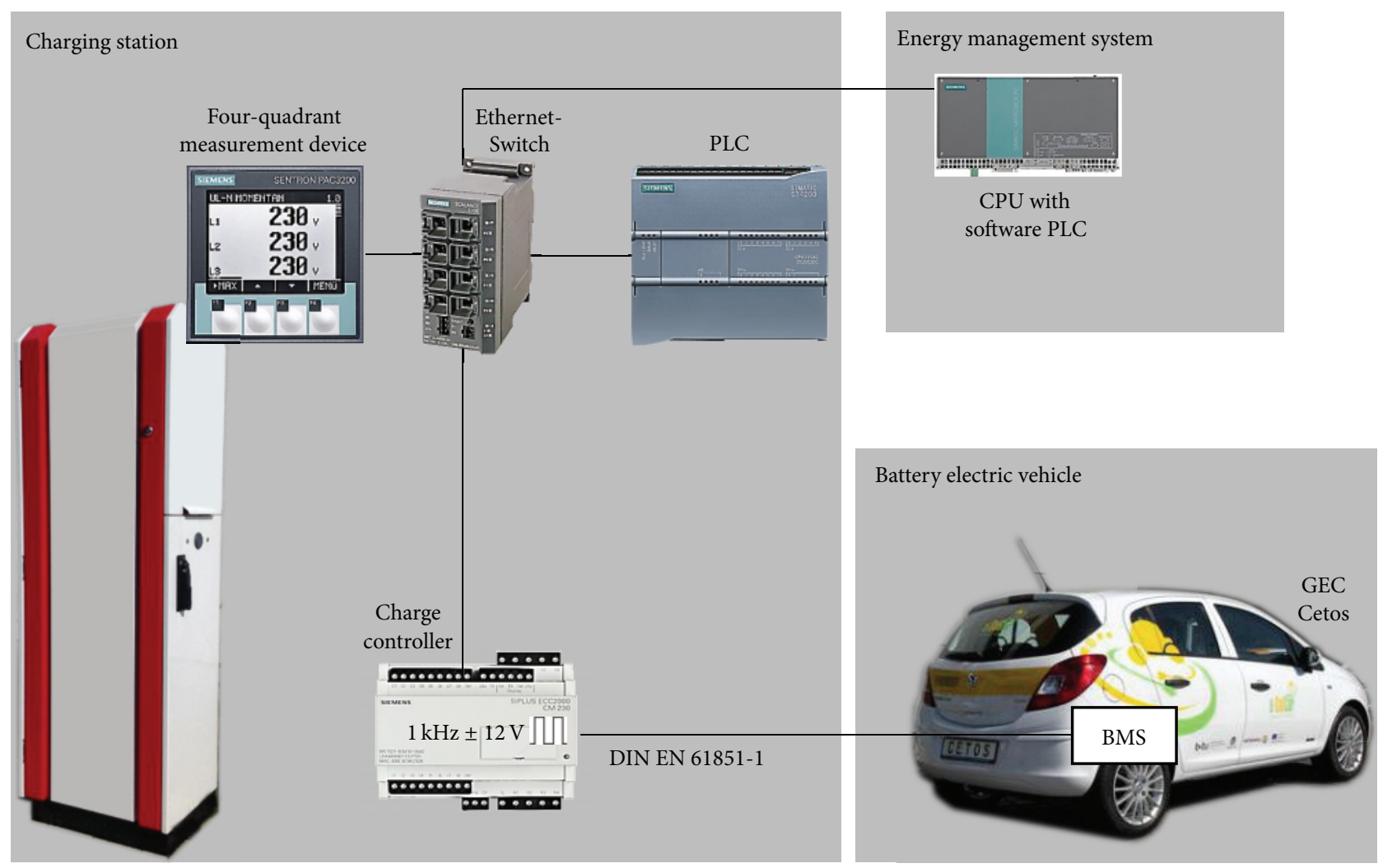

- Communication link

GEC: German E-Cars

FIGURE 2: Charging stations elements and communication.

TABLE 1: Characteristics of mode 2 and mode 3 charging according to one German E-Cars Cetos.

\begin{tabular}{lcc}
\hline Charging level & 2 & 3 \\
\hline $\begin{array}{l}\text { Socket type in the charging } \\
\text { station }\end{array}$ & Schuko socket & Type 2 socket \\
$\begin{array}{l}\text { Power delivery } \\
\text { Nominal energy stored in }\end{array}$ & One-phase & Three-phase \\
$\begin{array}{l}\text { Li-ion battery in kWh } \\
\text { Maximal charging current of a } \\
\text { vehicle in A }\end{array}$ & 17.1 & 17.1 \\
$\begin{array}{l}\text { Maximal charging power in kW } \\
\text { Communication with the } \\
\text { vehicle over }\end{array}$ & 3.06 & 14.0 \\
$\begin{array}{l}\text { Smart meter } \\
\text { Controllable through EMS }\end{array}$ & ICCB & EVSE \\
$\begin{array}{l}\text { Controllable minimal charging } \\
\text { power in kW }\end{array}$ & No & Yes \\
Minimum charging duration & $5 \mathrm{~h} 35$ min & $1 \mathrm{~h} 16 \mathrm{~min}$ \\
\hline
\end{tabular}

the German E-Car Cetos equipped with Li-ion batteries are summarized in Table 1.

The customer can choose freely between the two charging modes, as in Table 1. Accordingly, there are two corresponding charging curves. Usually, mode 3 charging is preferred due to higher power and lower charging time. The one-phase charging (mode 2 ) is seen as an emergency to be used when mode 3 is not available due to technical problems.

The emergency charging cannot be controlled, it is called "dumb charging." After switching on, the maximal current charging is provided to the vehicle until the BMS starts the balancing phase. During this phase a small current is used to balance the voltage between various cells. In order to protect the battery a heating phase is launched if the temperature falls below $3^{\circ}$ Celsius. The heating process is governed by the BMS in the vehicle and cannot be influenced by external control. The one-phase heating works with a nominal power $P=350 \mathrm{~W}(I=1.52 \mathrm{~A})$ until the temperature of $3^{\circ}$ Celsius is reached. The duration of heating is stochastically affected by the battery temperature and environment temperature. After the heating, the main charging phase starts, as shown in Figure 3.

All load curves are determined by the common CCCVload profile for Li-ion cell charging [21]. Mode 3 charging is characterised through three-phase currents and the controllability of the process realised by the EVSE. A flexible load management is possible resulting in higher charging power and shorter charging times. Additionally, only one charger is used during the final balancing phase. A typical charging curve is shown in Figure 4. 


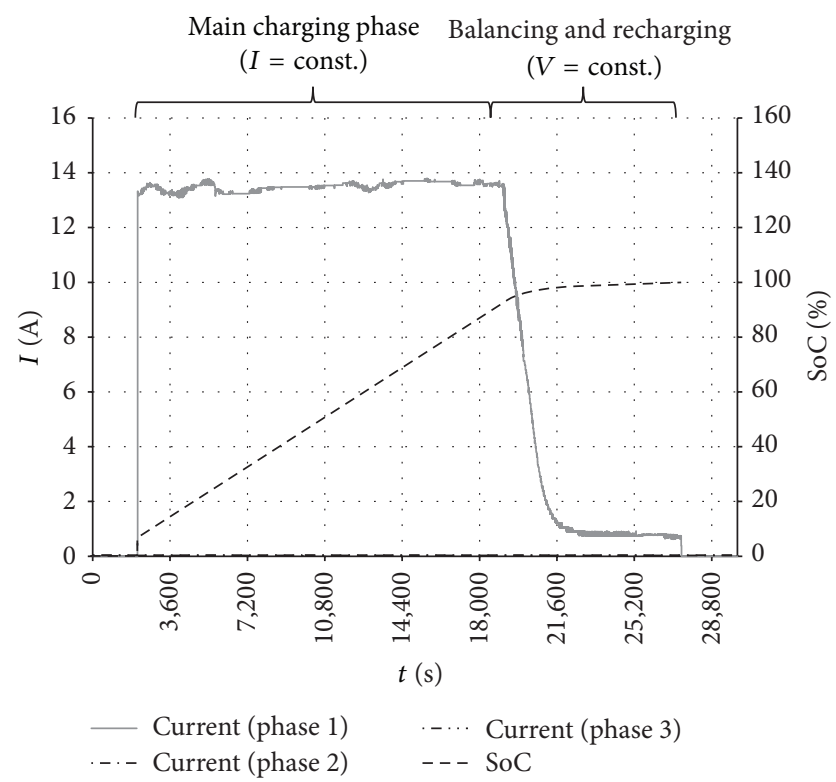

Figure 3: Typical charging curve of German E-Cars Cetos for charging mode 2 .

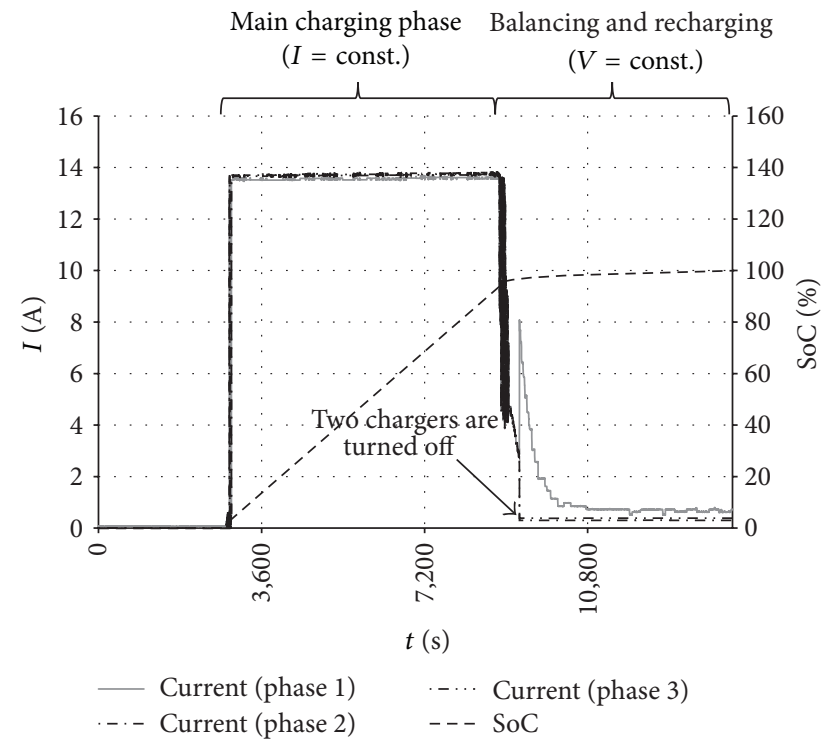

FIgure 4: Typical charging curve of German E-Cars Cetos for charging mode 3 .

The exponential reduction of the charging current reduces the efficiency factor of the charger in the electric vehicle. The shutdown of two chargers helps to make the charge process more effective and increase the efficiency factor.

\section{Assessment of Measured Power Curves}

The assessment and computations were aimed at an adequate characterisation of the residual load. The difference between the absolute PV system power output $\left(\left|P_{\text {renewable }}\right|\right)$ and the absolute demand of all charging stations connected to the microgrid $\left(\left|P_{\text {load }}\right|\right)$ can be expressed as

$$
P_{\text {res }}=\left|P_{\text {load }}\right|-\left|P_{\text {renewable }}\right| \text {. }
$$

According to $(1)$ the residual power $\left(P_{\text {res }}\right)$ cannot be delivered by the renewable source and has to be covered from conventional energy sources.

In the particular case of the described MG no separate generator or storage facility was connected. However, the microgrid could be connected over a transformer to the local public grid serving as source or sink for the residual power. A guarantied balanced islanded operation of the MG is possible only with a storage unit sized according to the levels and variations of residual power.

According to the goal of a balanced operation of the MG a differentiation between positive and negative residual power is needed. The residual power is positive, if the demand exceeds renewable power generation within the MG (undercoverage) [22]:

$$
\left|P_{\text {renewable }}\right|<\left|P_{\text {load }}\right| \text {. }
$$

The MG is balanced when the power generation exactly matches his demands:

$$
\left|P_{\text {renewable }}\right|=\left|P_{\text {load }}\right| \text {. }
$$

A negative residual power (overcoverage) results from $\mathrm{PV}$ generation exceeding the charging stations demand:

$$
\left|P_{\text {renewable }}\right|>\left|P_{\text {load }}\right| \text {. }
$$

A winter (January 2014) and a spring (May 2014) day were selected for presentation in this paper and represented through data of active power measured with one-second resolution. In a further step, the relatively short one-day period was extended to one-week observation. An average value over the course of the week was computed for every time instant of a day. The data collected at weekends were neglected and regarded as nonrepresentative due to missing charging of the cars at weekends (holidays).

The summarized analysis of active power in the PV system and in the CSP is presented in Table 2. The variance in Table 2 corresponds to the particular arithmetic average of power, not to installed power.

The PV generation depends directly on the irradiation values. Clouds, shadowing, and irradiance variations result in high power gradients. The standard deviation and variance along with the average value of power (Table 2) characterise the changes in the daily power curve (Figure 5).

Typically, the first car arrives in the early morning hours and starts to charge. The last one departs in the evening with a charged battery. The total load of the CSP is a superposition of all loading curves of the day, which may be of two different types (Figures 3 and 4). The positive slope of the load curve is a result of high power gradients of the connecting cars. The cars start to load with the maximal allowed current. The negative slope is a result of a low current balancing phase and recharging, which causes high variations form the maximal load point until the end of charging. 
TABLE 2: Results of the statistical assessment of active power in PV and CSP in winter and spring.

\begin{tabular}{|c|c|c|c|c|}
\hline \multirow{2}{*}{ Spring day } & \multicolumn{2}{|c|}{ A day } & \multicolumn{2}{|c|}{ An average day } \\
\hline & PV & CSP & PV & CSP \\
\hline Measurement values per day & 86,400 & 86,400 & 86,400 & 86,400 \\
\hline Installed power in $\mathrm{kW}$ & 116.6 & 110.8 & 116.6 & 110.8 \\
\hline Arithmetic average in $\mathrm{kW}$ & 16.86 & 5.41 & 23.46 & 3.97 \\
\hline Standard deviation in $\mathrm{kW}$ & 25.28 & 11.23 & 28.13 & 7.65 \\
\hline Variance in $\mathrm{kW}^{2}$ & 639.23 & 126.06 & 791.32 & 58.58 \\
\hline Maximum power in $\mathrm{kW}$ & 100.61 & 54.41 & 85.27 & 41.12 \\
\hline Minimum power in $\mathrm{kW}$ & 0.00 & 0.23 & 0.00 & 0.23 \\
\hline Maximum $\partial P / \partial t$ in $\mathrm{kW} / \mathrm{s}$ & 33.08 & 12.92 & 6.62 & 3.02 \\
\hline Energy in $\mathrm{kWh}$ & 404.72 & 129.85 & 563.11 & 95.18 \\
\hline Energy relation based on load & 3.12 & 1.00 & 5.92 & 1.00 \\
\hline \multirow{2}{*}{ Winter day } & \multicolumn{2}{|c|}{ A day } & \multicolumn{2}{|c|}{ An average day } \\
\hline & PV & CSP & PV & CSP \\
\hline Measurement values per day & 86,400 & 86,400 & 86,400 & 86,400 \\
\hline Installed power in $\mathrm{kW}$ & 116.6 & 110.8 & 116.6 & 110.8 \\
\hline Arithmetic average in $\mathrm{kW}$ & 2.84 & 5.70 & 1.29 & 3.58 \\
\hline Standard deviation in $\mathrm{kW}$ & 5.90 & 8.69 & 2.36 & 4.69 \\
\hline Variance in $\mathrm{kW}^{2}$ & 34.80 & 75.52 & 5.59 & 22.00 \\
\hline Maximum power in $\mathrm{kW}$ & 51.94 & 43.37 & 12.97 & 25.41 \\
\hline Minimum power in $\mathrm{kW}$ & 0.00 & 0.41 & 0.00 & 0.46 \\
\hline Maximum $\partial P / \partial t$ in $\mathrm{kW} / \mathrm{s}$ & 5.77 & 6.17 & 1.15 & 1.98 \\
\hline Energy in kWh & 68.26 & 136.88 & 30.89 & 85.88 \\
\hline Energy relation based on load & 0.50 & 1.00 & 0.36 & 1.00 \\
\hline
\end{tabular}

The arithmetic mean value of the PV power at a particular day in spring is approximately 3.1 times higher than the CSP mean load value. In order to guarantee an energetic balance between PV generation and CSP load it would be possible to reduce the installed PV power $P_{\text {peak }}$ to $37.61 \mathrm{~kW}_{\text {peak }}$. However, the high values of standard deviation and variance indicate a highly stochastic nature of the power balance (Table 2). Even if the balance would be guaranteed for average power values, the residual power would rise due to reduction and high variation in the PV generation. The above observation is even more distinctive for the power values averaged over one week; the ratio of PV to CSP power is 5.9.

The situation is completely different on a winter day (Figure 6). The arithmetic average power at $\mathrm{PV}$ is smaller than that at CSP by the ratio of 0.5 . In order to cover the average demand of CSP at that particular day it would be necessary to roughly double the installed peak power of the PV system to $233.20 \mathrm{~kW}_{\text {peak }}$. The assessment of the average day (one-week observations) yields even worse ratio between CSP demand and PV output (factor 0.36).

This observations shows that an energy storage unit is unavoidable for the enhancement of CSP operation efficiency. The storage reduces the residual power in the MG and reduces the involvement of the public distribution grid. The storage unit has to be dimensioned according to the performance of the existing power grid. The analysis and characterisation of the residual power in a statistical manner are a key issue for the adequate design and dimensioning of the storage.
The residual power of a particular day and an averaged week in winter and spring shown in Figure 6 are an example and starting point for further considerations.

The corresponding physical and statistical values are presented in a compact manner in Table 3.

The arithmetical average value of the residual power on a spring day is negative, because the PV system delivers energy over a longer time period in the amount lower than the load that has to be supplied. Accordingly, there is a power flow from the MG to the public distribution system.

A different situation can be observed on a winter day. The arithmetic average value of residual power is positive; that is, the CSP needs more power than the PV system can generate. The main reason is reduced solar irradiation during the winter season in the northern hemisphere. Additionally, the base power of the CSP goes higher due to the necessary protective heating of electronic devices in the charging stations and connected electric vehicles. The batteries in the cars also need a heating phase before charging what increases the power level.

Power consumption from the public distribution grid at the early hours of a spring day is significant due to the unavoidable base power and arrival of discharged vehicles. Later in the day, the PV delivers sufficient power to the CSP to provide full coverage and to feed the surplus into the public grid. The power fluctuations of the superimposed load curve go directly into the grid. It should be noticed that from a one-day perspective the standard deviation, variance, and maximal power gradient visibly increase as a result of the mentioned superposition. This results in higher power volatility at the grid connecting point. The power variations are higher than those of the individual actors to be considered separately. In the case of an average day it is true for the maximal power gradient. Standard deviation and variance were reduced due to the performed averaging.

In order to level the difference between generation and loads on that particular spring day an energy storage unit with an energy capacity of $274.87 \mathrm{kWh}$ or $467.93 \mathrm{kWh}$ is needed. The energy capacity increases for the averaged day (values of 5 days included), because a higher sun exposure occurred along with reduced vehicle charging demand. The power of the storage unit would have to be $99.93 \mathrm{~kW}$ or $82.79 \mathrm{~kW}$, respectively (see Table 3 ). Storage unit sizing is thus strongly influenced by the characteristics of the PV generation. The PV system determines here the upper physical limits.

A different scenario can be derived from the observation of a winter day. Over the course of a day there are periods when the PV system feeds the public grid. However, the average power is not sufficient to feed the CSP sufficiently (see Table 2). The energy deficit must be covered by the public grid which is anyway more stressed than in summer. As previously, the maximal power gradient value of a day increases as a result of the superposition of the PV and CSP characteristics. Standard deviation, variance, and average value of power increase in relation to PV and decrease in relation to CSP. The maximal gradient of the residual power computed for the average day is constant due to superposition. Average value, standard deviation, and variance of power increase in relation to $\mathrm{PV}$ and decrease 


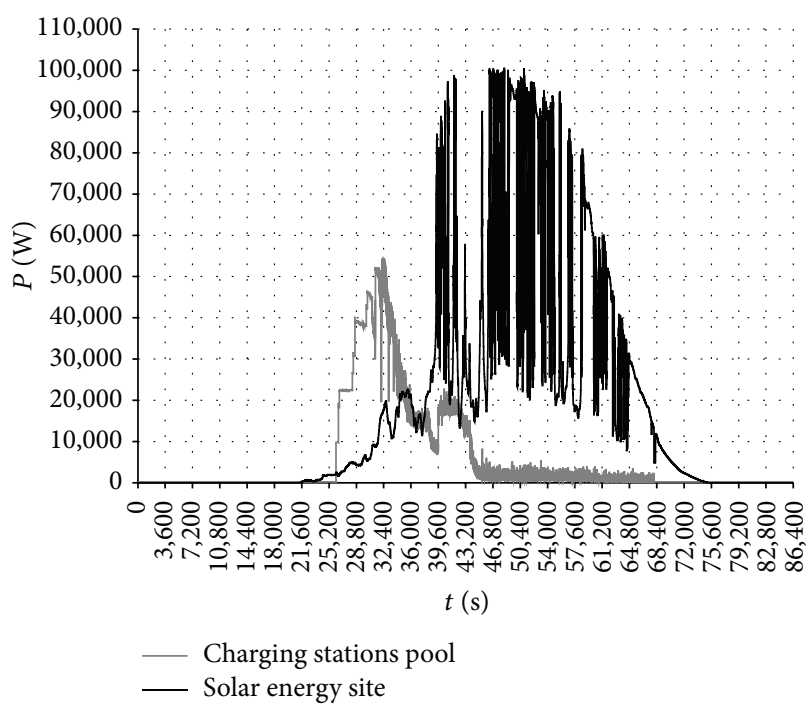

(a)

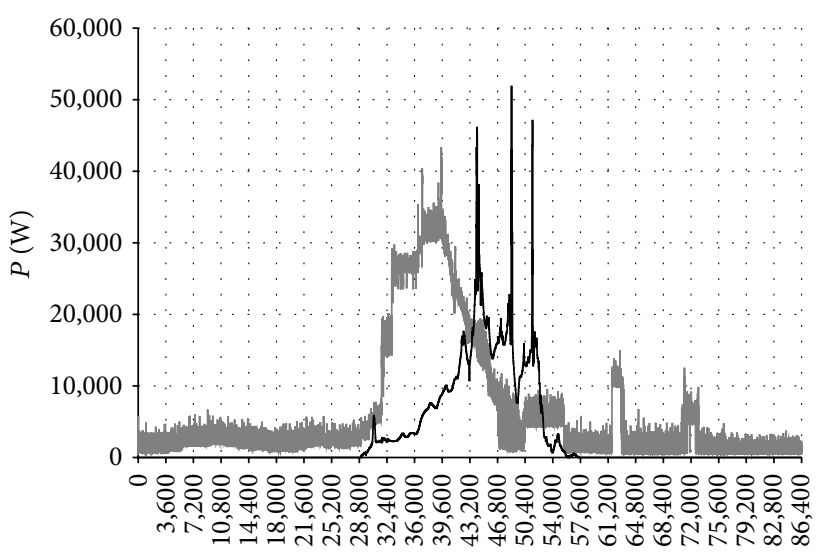

$t(\mathrm{~s})$

- Charging stations pool

Solar energy site

(c)

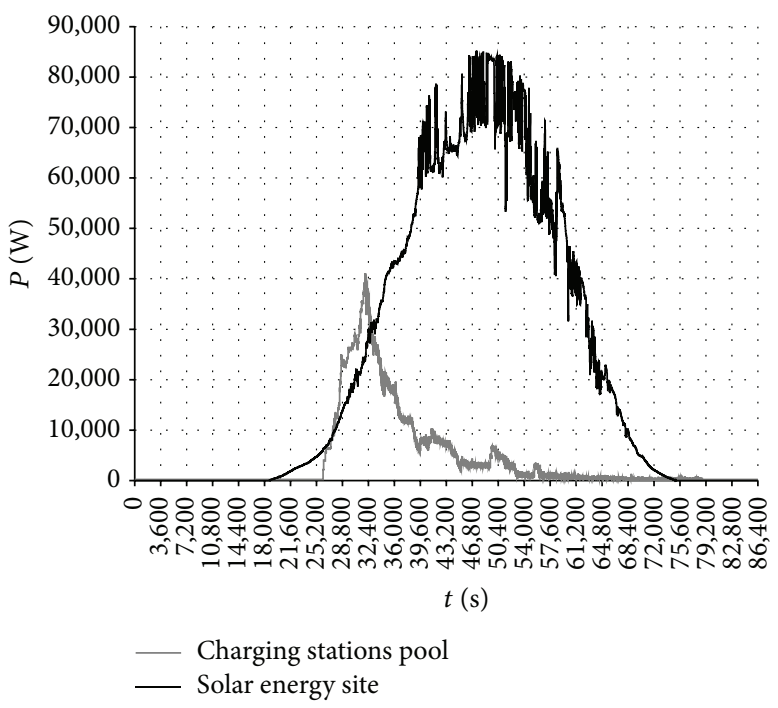

(b)

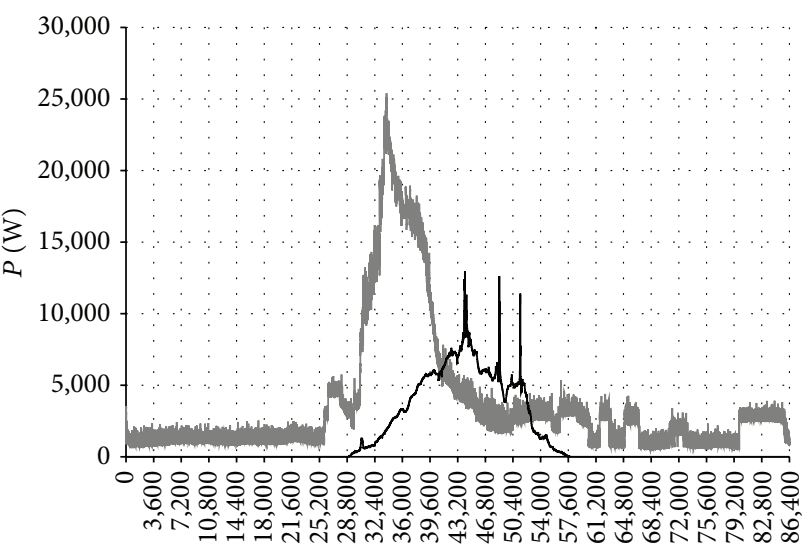

$t(\mathrm{~s})$

- Charging stations pool

_ Solar energy site

(d)

FIGURE 5: Typical daily power curve of the CSP and PV generator: (a) one-day values, spring; (b) values averaged over one week, spring; (c) one-day values, winter; (d) values averaged over one week, winter.

in relation to CSP. This behaviour is similar to a spring day.

Once again, to level the difference between generation and demand on that particular winter day an energy storage unit with a power capacity of $68.62 \mathrm{kWh}$ or $54.99 \mathrm{kWh}$ is needed. The energy capacity of the anticipated storage unit decreases for the average day. It is due to a persistent tendency on subsequent days showing lower irradiation and higher power demand, as on the particular one day shown before. The corresponding power of the anticipated storage unit should be $51.00 \mathrm{~kW}$ or $23.50 \mathrm{~kW}$, respectively (see Table 3 ). The dimensioning of the storage performed using winter data is more related to the CSP characteristic than in the spring. Relatively small contribution of the PV system has no influence on the upper power limit. Moreover, the storage can be significantly smaller in winter than in spring due to smaller PV contribution and higher energy consumption by the CSP.
At average week day in spring the own coverage reaches a maximum of $86.35 \%$; the minimum is due to the low sunlight at the average winter week day $25.41 \%$ (see Table 3 ).

If the MG operator seeks to guarantee a coverage of the positive residual power and thus only the demand that is not covered by the PV system, as it is shown in Figure 7, the storage unit could be even smaller dimensioned.

As it can be seen in Table 3, from a particular spring day perspective, the necessary energy is reduced to $64.00 \mathrm{kWh}$ and with respect to the average spring day to only $12.99 \mathrm{kWh}$. The reduction is associated with a significantly better coverage of the load by the PV on the remaining days, of which the averaged one day was formed. The power of the storage unit decreased in a similar manner from $43.50 \mathrm{~kW}$ to $17.13 \mathrm{~kW}$. The maximum power gradients decreased as well. The storage unit dimensioning results from the assumption of positive residual power coverage priority and follows the power 


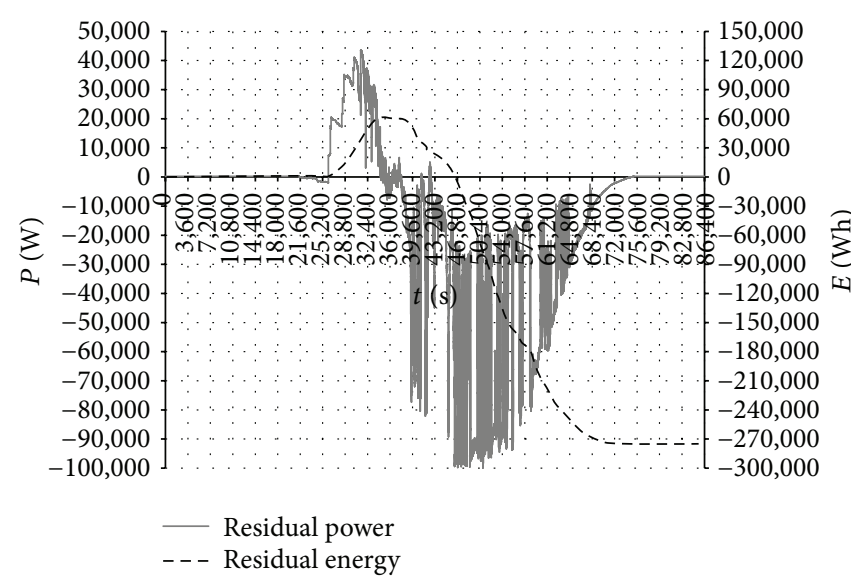

(a)

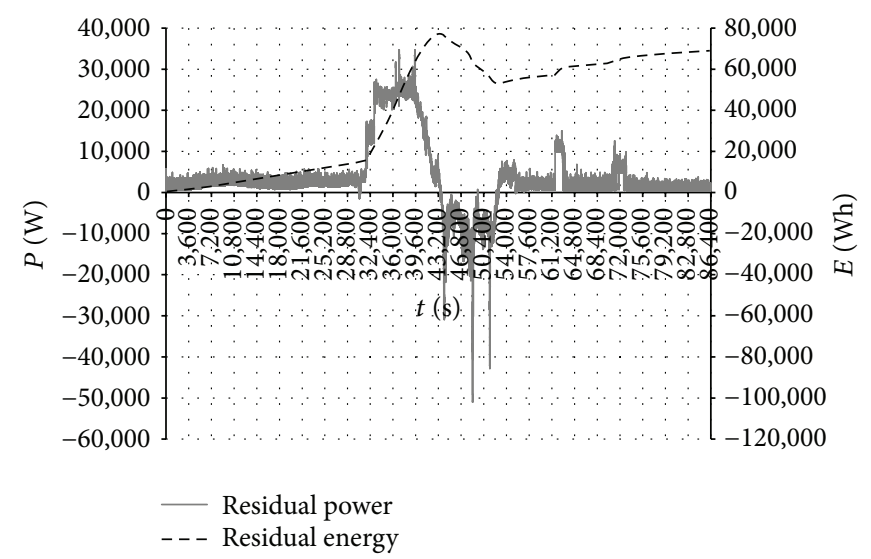

(c)

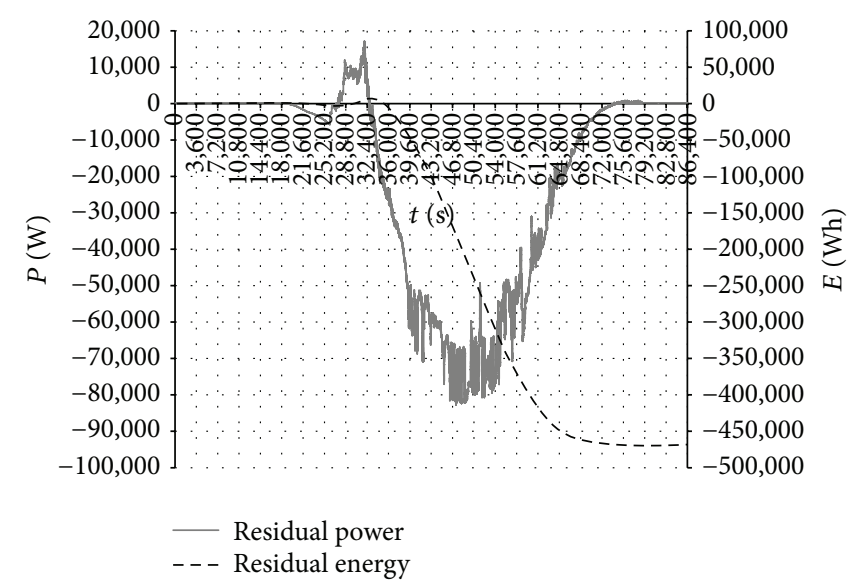

(b)

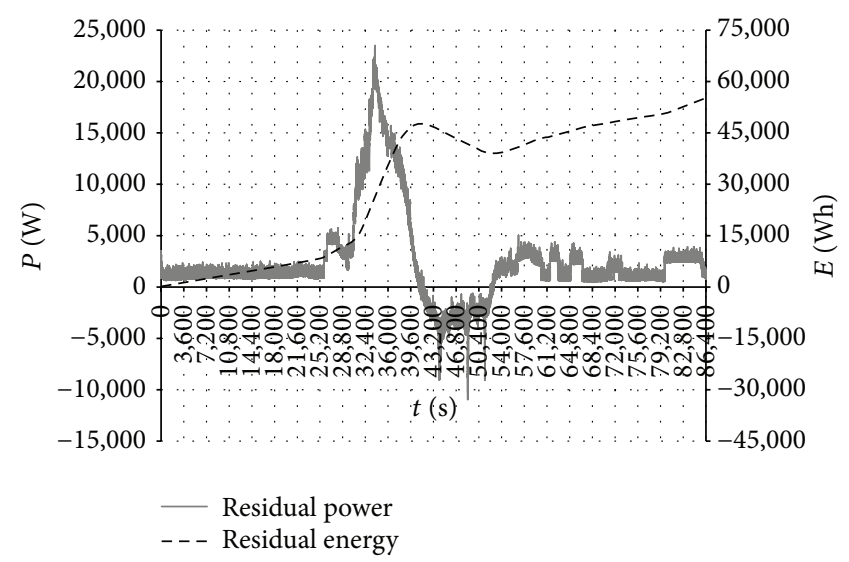

(d)

FIGURE 6: Typical daily residual power curve of the CSP and PV generator: (a) one-day values, spring; (b) values averaged over one week, spring; (c) one-day values, winter; (d) values averaged over one week, winter.

curves. It should be stressed that the energy delivered by the storage unit could be fed through the PV system and so the storage could be reloaded on a daily basis.

The positive residual power is related to the PV system output. Accordingly, the storage capacity must be higher in winter in order to cover the CSP demand. Considering the presented winter day the anticipated storage capacity should be $92.83 \mathrm{kWh}$. In the case of an average winter day $64.06 \mathrm{kWh}$ is enough. The storage capacity is also higher as on corresponding spring day. The power in winter was $34.72 \mathrm{~kW}$ for a day and $23.50 \mathrm{~kW}$ for an average day, respectively.

The histograms show the absolute and relative percentages of data points as a function of defined power classes (groups). Values with $P \leq 0 \mathrm{~W}$ are not considered because they are not associated with a shortage. Furthermore, in spring active power $P<500 \mathrm{~W}$ was represented in one class as it represents the base load of the CSP. In winter, this limit due to the higher base load and additional heating power is raised to $P<5,500 \mathrm{~W}$. The classification was made for power values $P \geq 500 \mathrm{~W}$ and $P \geq 5,500 \mathrm{~W}$, respectively, with $2,500 \mathrm{~W}$ increments.

The quadratic regression utilising the Gauss approach returns the smallest quadratic differences between power classes (groups) and the cumulated relative percentage of the data points. The results are shown in Table 4 and indicates strong tendencies and characteristic features. It is advisable to design and dimension the storage unit in accordance with the above considerations.

Table 5 presents residual power values in relation to the dimensioning of a storage unit.

Considering a $90 \%$ guarantee of power coverage on a spring day (Table 5) it is possible to reduce the power of a storage device to $40.50 \mathrm{~kW}$ for the particular day and to only $13.00 \mathrm{~kW}$ for the averaged day. Accordingly, the needed storage capacity can be reduced to $57.60 \mathrm{kWh}$ and $11.69 \mathrm{kWh}$, respectively.

The same assumption of $90 \%$ coverage in winter (Table 5) requests different storage capacity in comparison with spring season data. The power of the storage unit should be $31.25 \mathrm{~kW}$ or $21.15 \mathrm{~kW}$, respectively. The corresponding energy storage capacity is $83.55 \mathrm{kWh}$ or $57.65 \mathrm{kWh}$. Generally, the winter period requires higher energy storage capacity for the coverage of positive residual power in the MG than the spring period.

The definition of an allowed level of power storage coverage has to be decided by the MG operator or the utility 
TABLE 3: Results of the statistical assessment of the residual power on a winter day and a spring day.

\begin{tabular}{|c|c|c|c|c|}
\hline \multirow{2}{*}{ Spring day } & \multicolumn{2}{|c|}{ A day } & \multicolumn{2}{|c|}{ An average day } \\
\hline & Residual power & Positive residual power & Residual power & Positive residual power \\
\hline Measurement values per day & 86,400 & 86,400 & 86,400 & 86,400 \\
\hline Arithmetic average in $\mathrm{kW}$ & -11.45 & 2.67 & -19.50 & 0.54 \\
\hline Standard deviation in $\mathrm{kW}$ & 27.55 & 8.29 & 27.39 & 2.01 \\
\hline Variance in $\mathrm{kW}^{2}$ & 758.92 & 68.72 & 750.19 & 4.04 \\
\hline Maximum power in $\mathrm{kW}$ & 43.50 & 43.50 & 17.13 & 17.13 \\
\hline Minimum power in $\mathrm{kW}$ & -99.93 & 0.00 & -82.79 & 0.00 \\
\hline Maximum $\partial P / \partial t$ in $\mathrm{kW} / \mathrm{s}$ & 33.16 & 12.92 & 6.84 & 3.02 \\
\hline Energy in kWh & -274.87 & 64.00 & -467.93 & 12.99 \\
\hline Own coverage of load in $\%$ & - & 50.71 & - & 86.35 \\
\hline \multirow{2}{*}{ Winter day } & \multicolumn{2}{|c|}{ A day } & \multicolumn{2}{|c|}{ An average day } \\
\hline & Residual power & Positive residual power & Residual power & Positive residual power \\
\hline Measurement values per day & 86,400 & 86,400 & 86,400 & 86,400 \\
\hline Arithmetic average in $\mathrm{kW}$ & 2.86 & 3.87 & 2.29 & 2.67 \\
\hline Standard deviation in $\mathrm{kW}$ & 8.05 & 6.72 & 4.39 & 4.01 \\
\hline Variance in $\mathrm{kW}^{2}$ & 64.73 & 45.18 & 19.28 & 16.12 \\
\hline Maximum in $\mathrm{kW}$ & 34.72 & 34.72 & 23.50 & 23.50 \\
\hline Minimum in kW & -51.00 & 0.00 & -10.94 & 0.00 \\
\hline Maximum $\partial P / \partial t$ in $\mathrm{kW} / \mathrm{s}$ & 6.77 & 6.17 & 1.98 & 1.98 \\
\hline Energy in $\mathrm{kWh}$ & 68.62 & 92.83 & 54.99 & 64.06 \\
\hline Own coverage of load in \% & - & 32.18 & - & 25.41 \\
\hline
\end{tabular}

TABLE 4: Regression equations for the winter and spring days.

\begin{tabular}{lcc}
\hline Period & Quadratic regression & Coefficient of determination $\left(R^{2}\right)$ \\
\hline Spring & & 0.9742 \\
$\quad$ A day & $y=0.0005 x^{2}+0.0477 x-0.1229$ & 0.9638 \\
$\quad$ An average day & $y=-0.0213 x^{2}+0.4083 x-0.9357$ & 0.9382 \\
Winter & $y=-0.0038 x^{2}+0.171 x-0.7396$ & 0.9878 \\
A day & $y=-0.0201 x^{2}+0.4832 x-1.8913$ & \\
An average day & & \\
\hline
\end{tabular}

operating the distribution grid. Certainly, financial aspects induced by the tariffs regulation have a significant influence on the coverage limit definition.

From the engineering perspective, various scenarios can be derived from the approximation curves given in Table 4. The relationship between storage size and anticipated positive residual power coverage is expressed through an equation resulting from statistical observations (Table 4).

There is a trade-off between the investment cost of a storage unit and anticipated residual power coverage. An optimization procedure should also include the tariff regulations defining the financial conditions.

\section{Conclusion}

A detailed analysis of the power data records showed that residual powers in the MG depend on the season of the year and yield high short time variations. If the electric vehicles charge in an uncontrolled unidirectional manner, the residual load cannot be minimized by a charging power time shift or by a centralized charging level control. PV system is mainly influenced by long and short time variations of the solar irradiation levels. The charging of electric vehicles is mainly characterised by the arrival and departure times influencing the simultaneity of superimposed charging loads. Environmental factors, for example, ambient temperature, affect the charging process.

The use of a fast responding energy storage system would contribute significantly to the reduction of the residual power and its variations as well.

The statistical analysis of the data enabled heuristic approach to the sizing problem of a storage unit. Two different observation periods were analysed in two different seasons of the year. The constraints imposed by energetic and physic characteristics of all the actors in the MG must be regarded in the sizing approach. The sizing is also strongly dependent on the selected observation period and data averaging approach. Nevertheless, suitable ranges of values arise, from which a particular solution can be chosen. 


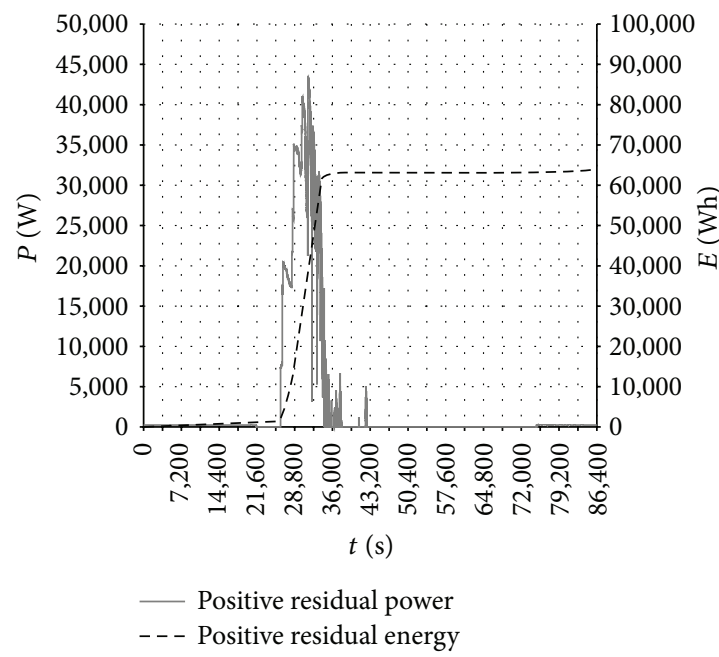

(a)

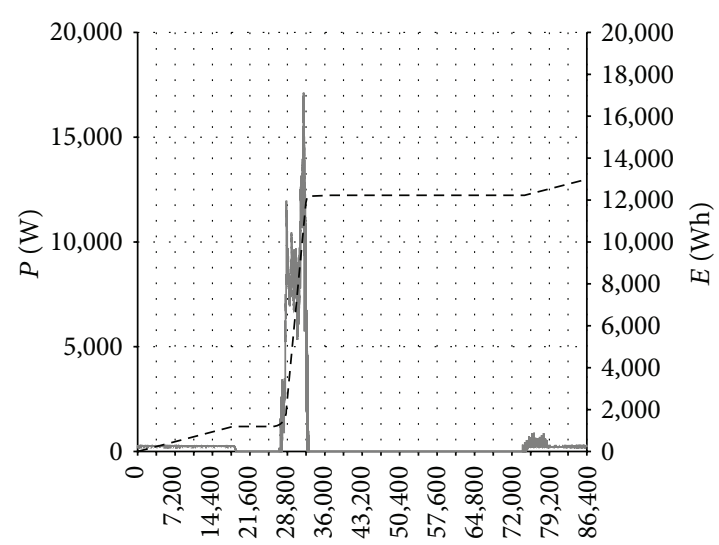

$t$ (s)

_ Positive residual power

- - - Positive residual energy

(c)

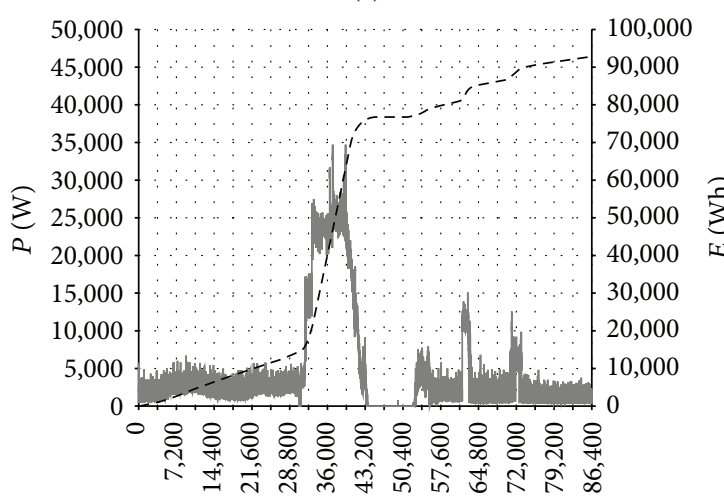

$t(\mathrm{~s})$

_ Positive residual power

- - - Positive residual energy

(e)

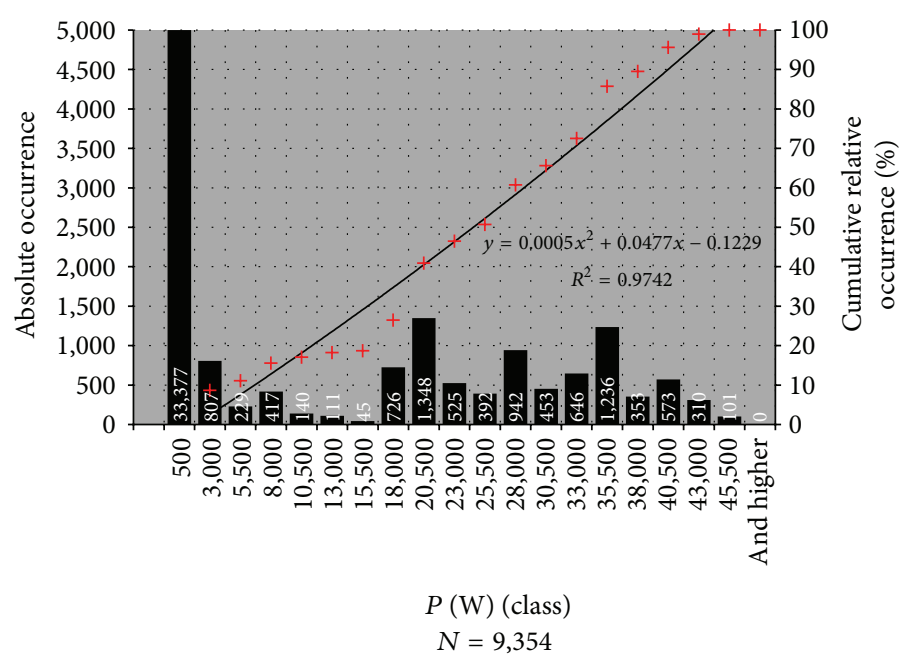

- Absolute occurrence - Quadratic regression

(b)

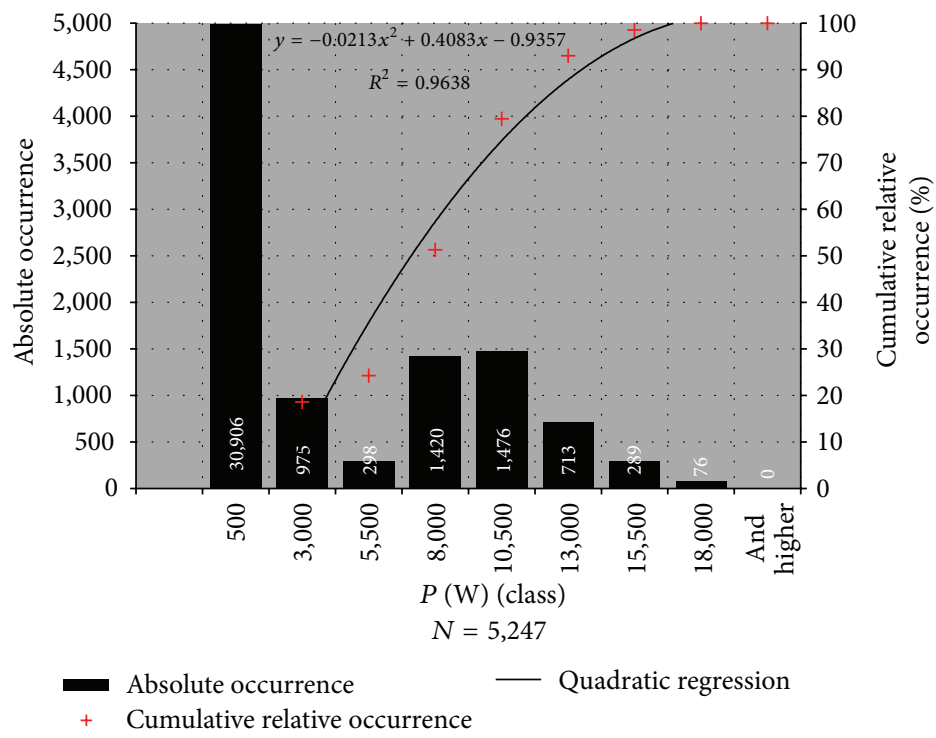

(d)

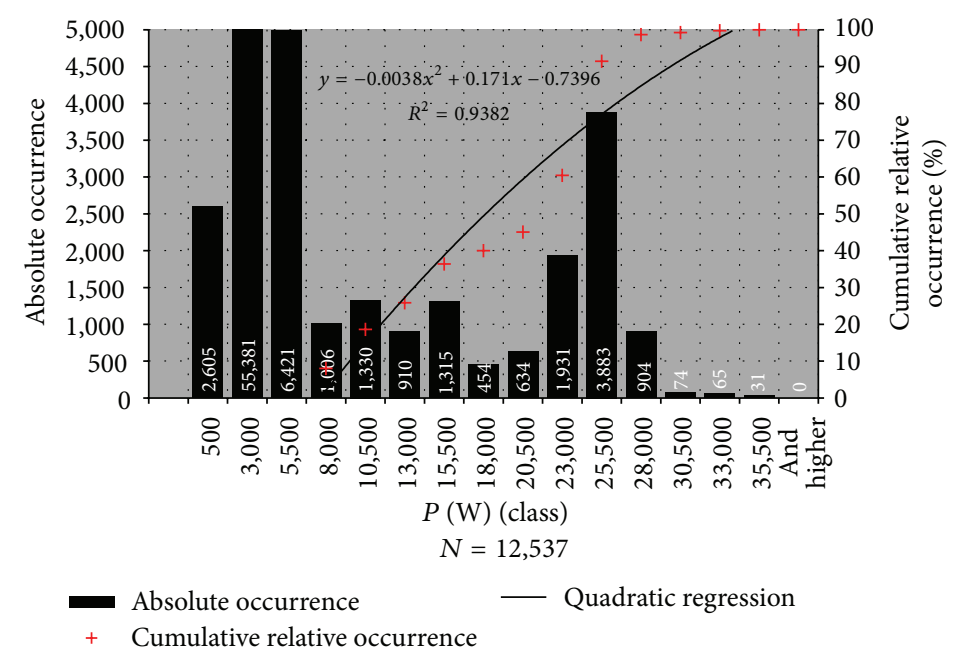

(f)

Figure 7: Continued. 


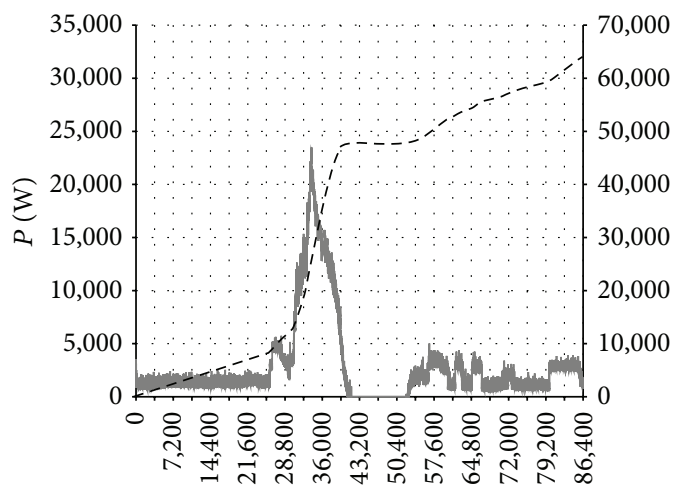

$t(\mathrm{~s})$

- Positive residual power

- - - Positive residual energy

(g)

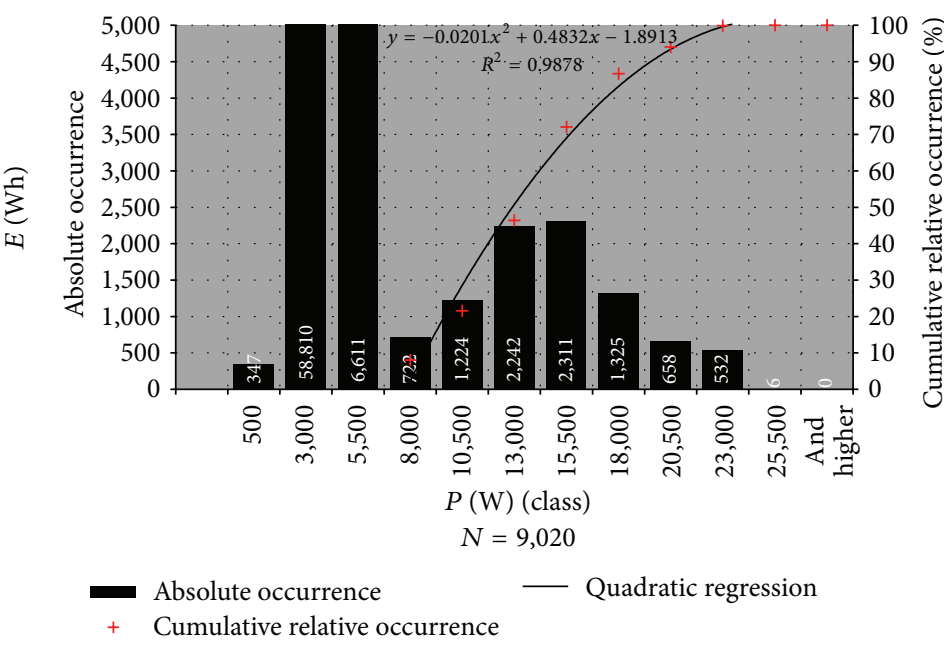

(h)

FIGURE 7: Positive residual power along with residual energy and the histogram of positive residual power: (a) residual power, one-day values, spring; (b) histogram of one-day residual power, spring; (c) residual power, averaged day, spring; (d) histogram of averaged day residual power, spring; (e) residual power, one-day values, winter; (f) histogram of one-day residual power, winter; (g) residual power, averaged day, winter; (h) histogram of averaged day residual power, winter.

TABLE 5: Residual power values implications for storage unit dimensioning.

\begin{tabular}{|c|c|c|c|c|c|c|}
\hline \multirow{2}{*}{ Period } & \multicolumn{2}{|c|}{ Residual power } & \multicolumn{4}{|c|}{ Positive residual power } \\
\hline & A day & An average day & & & & \\
\hline \multicolumn{7}{|l|}{ Spring } \\
\hline Dimensioning in \% & 100 & 100 & 100 & 90 & 100 & 90 \\
\hline Power in $\mathrm{kW}$ & 99.93 & 82.79 & 43.50 & 40.50 & 17.13 & 13.00 \\
\hline Energy in kWh & 274.87 & 467.93 & 64.00 & 57.60 & 12.99 & 11.69 \\
\hline \multicolumn{7}{|l|}{ Winter } \\
\hline Dimensioning in \% & 100 & 100 & 100 & 90 & 100 & 90 \\
\hline Power in kW & 51.00 & 23.50 & 34.72 & 31.25 & 23.50 & 21.15 \\
\hline Energy in $\mathrm{kWh}$ & 68.62 & 54.99 & 92.83 & 83.55 & 64.06 & 57.65 \\
\hline
\end{tabular}

An exact and precise description of the charging loads correlated to the features of behavioural patterns of drivers increases the accuracy of sizing.

The research exhibits inherent statistical uncertainty; all energetic and physical system constraints of the individual components must be included in the simulation models. As a result, the statistical uncertainty is minimized and maximum reliability of results could be reached. The goal was to testify the characteristic of the residual power and thus the necessary storage capacity, to make most realistic representation. Above all, the weather-related seasonal correlations as well as the user behaviour pose the biggest challenge for the optimal combination of individual system components.

\section{Additional Points}

(i) There can be a relative high amount of residual power in MG with charging stations pool and PV system which varies over the behaviour of the components and the season; (ii) dumb charging leads to an insufficient use of the generated
PV energy of the described system; the deployment of an adequate storage can handle this problem; (iii) the superposition of PV and a CSP (with dumb charging) can increase negative effects on the public grid (power fluctuations); (iv) in spring no additional energy from other generating systems is needed; in winter on the basis of lower irradiance more energy is needed as the PV can offer; (v) in the observed spring periods a storage of almost $500 \mathrm{kWh}$ and $100 \mathrm{~kW}$ is needed to handle the rising power and energy in the MG; in total more energy is generated than used; (vi) on the other hand in the observed winter periods the storage can be much lesser; almost $70 \mathrm{kWh}$ and $50 \mathrm{~kW}$ are needed and in total more energy is needed than produced; (vii) the used lead acid storage is undersized in summer and oversized in winter; (viii) the optimal system configuration is dependent relationship between generation, load, and storage system taking into account the base load of the weather-related production and storage reserve; and (ix) the dumb charging of electric vehicles leads to strongly inefficient operation of the pv and storage system; the solution can be the smart charging of electric vehicles. 


\section{Competing Interests}

The authors declare that they have no competing interests.

\section{References}

[1] Federal Ministry of Education and Research, "National Electromobility Development Plan of the Federal Government," 2015 (German), http://www.bmbf.de/pubRD/nationaler_entwicklungsplan_elektromobilitaet.pdf.

[2] National Platform for Electric Mobility (NPE), "Progress Report 2014-Review of Pre-Market Phase," http://www.bmvi .de/SharedDocs/EN/Anlagen/VerkehrUndMobilitaet/Strasse/ NPE-progress-report-2014.pdf?__blob=publicationFile.

[3] M. A. S. Masoum, P. S. Moses, and S. Hajforoosh, "Distribution transformer stress in smart grid with coordinated charging of plug-in electric vehicles," in Proceedings of the IEEE PES Innovative Smart Grid Technologies (ISGT '12), vol. 30, pp. 1-8, Washington, DC, USA, January 2012.

[4] J. A. P. Lopes, F. J. Soares, and P. M. R. Almeida, "Integration of electric vehicles in the electric power system," 2011, http://ieeexplore.ieee.org/stamp/stamp.jsp?tp=\&arnumber $=5593864$.

[5] P. Richardson, D. Flynn, and A. Keane, "Impact assessment of varying penetrations of electric vehicles on low voltage distribution systems," 2010, http://ieeexplore.ieee.org/stamp/stamp .$j s p ?$ tp $=$ \&arnumber $=5589940$.

[6] K. O. Schallaböck and M. Fischedick, Mix of electric energy in the operation of electric vehicles. Partial Report under the Environmental Monitoring Research Priority Area, Electro-mobility model regions (German), March 2015, http://wupperinst.org/ uploads/tx_wupperinst/Elektromobilitaet_TB_Strommix.pdf.

[7] F. Locment, M. Sechilariu, and C. Forgez, "Electric vehicle charging system with PV grid-connected configuration: experimental tests of control and power management," in Proceedings of the 2010 IEEE Vehicle Power and Propulsion Conference (VPPC '10), Lille, France, September 2010.

[8] V. Marano and G. Rizzoni, "Energy and economic evaluation of PHEVs and their interaction with renewable energy sources and the power grid," in Proceedings of the IEEE International Conference on Vehicular Electronics and Safety (ICVES '08), pp. 84-89, IEEE, Columbus, Ohio, USA, September 2008.

[9] Y. Gurkaynak and A. Khaligh, "Control and power management of a grid connected residential photovoltaic system with plugin hybrid electric vehicle (PHEV) load," in Proceedings of the 24th Annual IEEE Applied Power Electronics Conference and Exposition (APEC '09), pp. 2086-2091, February 2009.

[10] X. Li, L. A. C. Lopes, and S. S. Williamson, "On the suitability of plug-in hybrid electric vehicle (PHEV) charging infrastructures based on wind and solar energy," in Proceedings of the IEEE Power and Energy Society General Meeting (PES '09), July 2009.

[11] F. Samweber, P. Nobis, and M. Gallet, "Simulation of Photovoltaic Power consumption with electric vehicles (Part 1)," BWK Das Energie-Fachmagazin, vol. 66, no. 1-2, pp. 66-69, 2014 (German).

[12] M. Mierau, D. Noeren, and F. Becker, "Potential Analysis of intelligent charging of electric vehicles with self-generated photovoltaic electricity in a private household"' (German), March 2015, http://www.ise.fraunhofer.de/de/downloads/pdffiles/paper/studie-potentialanalyse-der-intelligenten-ladungvon-elektrofahrzeugen-mit-eigenerzeugtem-photovoltaikstromin-einem-privathaushalt.pdf.
[13] J. A. P. Lopes, F. J. Soares, and P. M. R. Almeida, "Integration of electric vehicles in the electric power system," Proceedings of the IEEE, vol. 99, no. 1, pp. 168-183, 2011.

[14] Q. Jiang, M. Xue, and G. Geng, "Energy management of microgrid in grid-connected and stand-alone modes," IEEE Transactions on Power Systems, vol. 28, no. 3, pp. 3380-3389, 2013.

[15] I. S. Bayram, G. Michailidis, M. Devetsikiotis, and F. Granelli, "Electric power allocation in a network of fast charging stations," IEEE Journal on Selected Areas in Communications, vol. 31, no. 7, pp. 1235-1246, 2013.

[16] S. Bahramirad, W. Reder, and A. Khodaei, "Reliability-constrained optimal sizing of energy storage system in a microgrid," IEEE Transactions on Smart Grid, vol. 3, no. 4, pp. 2056-2062, 2012.

[17] F. Katiraei, R. Iravani, N. Hatziargyriou, and A. Dimeas, "Microgrids management," IEEE Power and Energy Magazine, vol. 6, no. 3, pp. 54-65, 2008.

[18] DENA, "Integration of renewable energies in the German European electricity market," (German), March 2015, http:// www.dena.de/fileadmin/user_upload/Presse/Meldungen/2012/ Endbericht_Integration_EE.pdf.

[19] "Plugs, socket-outlets, vehicle connectors and vehicle inletsconductive charging of electric vehicles-part 2: dimensional compatibility and interchangeability for a.c. pin and contacttube accessories (IEC 62196-2:2011)," Tech. Rep. DIN EN 621962, 2014.

[20] DIN, "Electric vehicle conductive charging system-part 1: general requirements (IEC 69/219/CD:2012)," DIN EN 61851-1, 2013.

[21] K. Young, C. Wang, L. Y. Wang et al., "Electric vehicle battery technologies," in Electric Vehicle Integration Into Modern Power Networks, R. Garcia-Valle and J. A. Pecas Lopes, Eds., pp. 15-56, Springer, Berlin, Germany, 1st edition, 2013.

[22] S. Kohler and A. Agricola, "Integration of renewable energies in the German European electricity market," (German), March 2015, http://www.vernunftkraft.de/de/wp-content/uploads/ 2012/12/zukunftsfragen_2012_1212_kohler.pdf. 

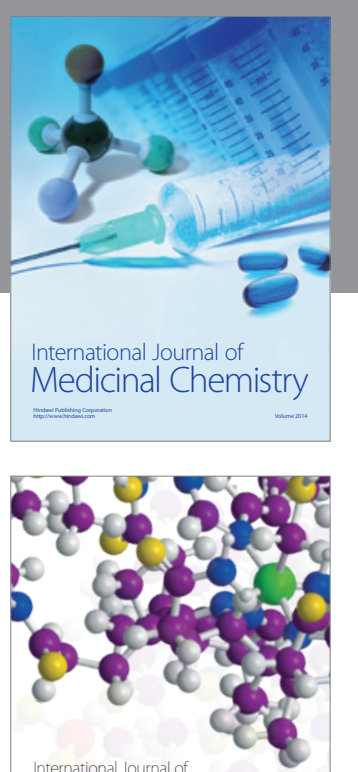

Carbohydrate Chemistry

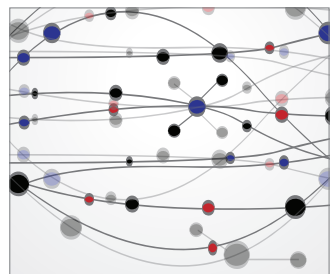

The Scientific World Journal
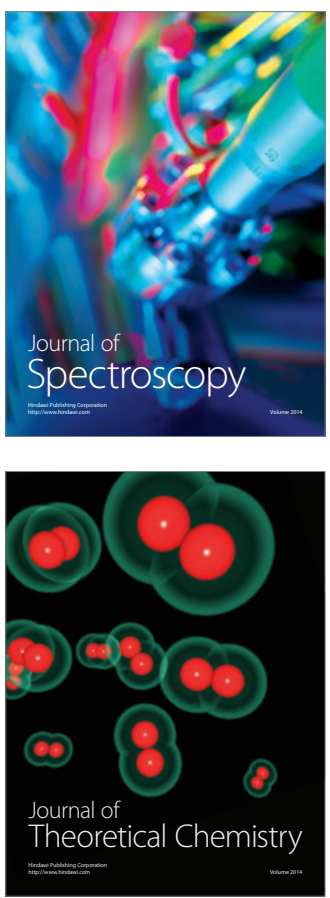
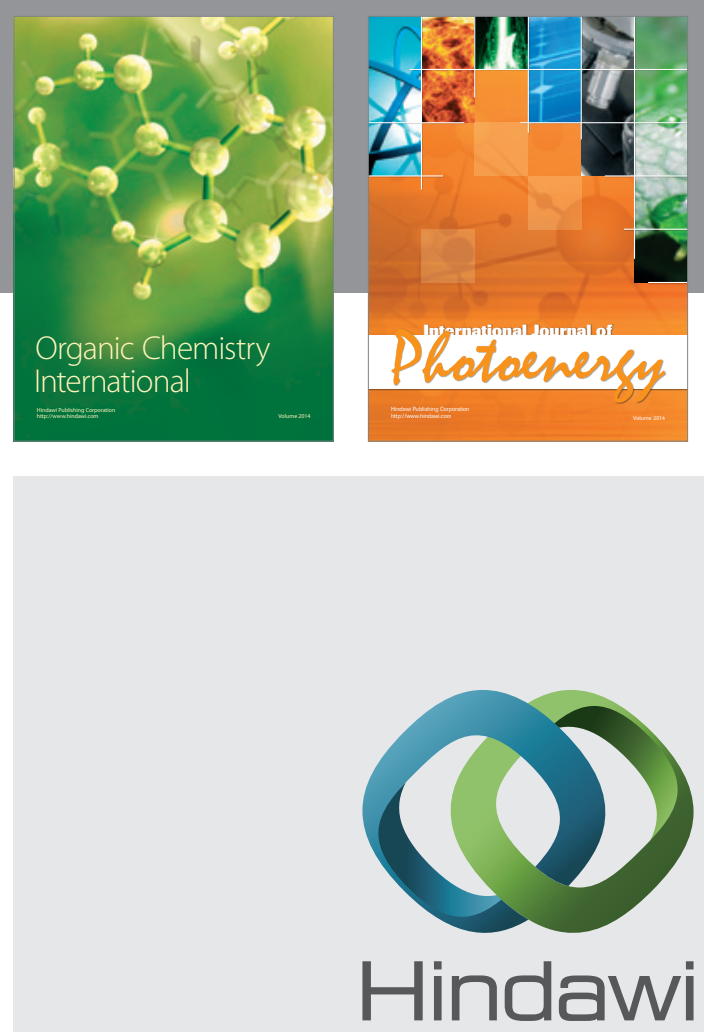

Submit your manuscripts at

http://www.hindawi.com

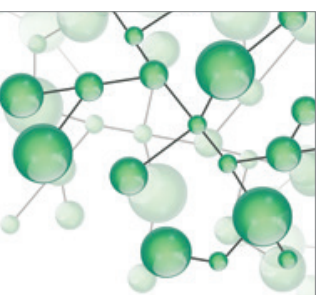

International Journal of

Inorganic Chemistry

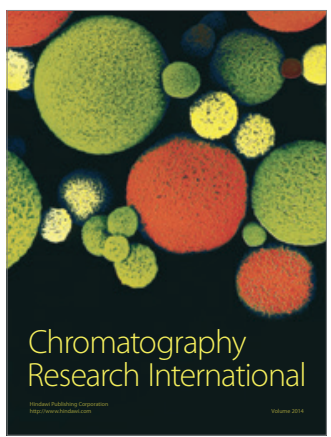

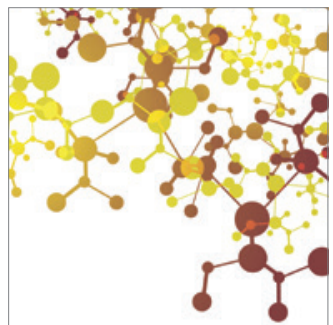

Applied Chemistry
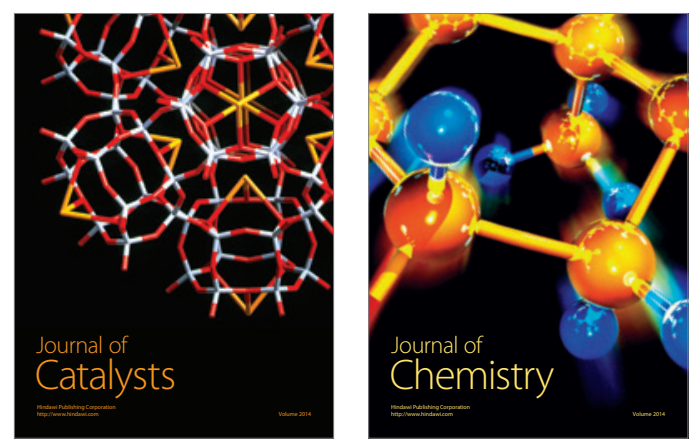
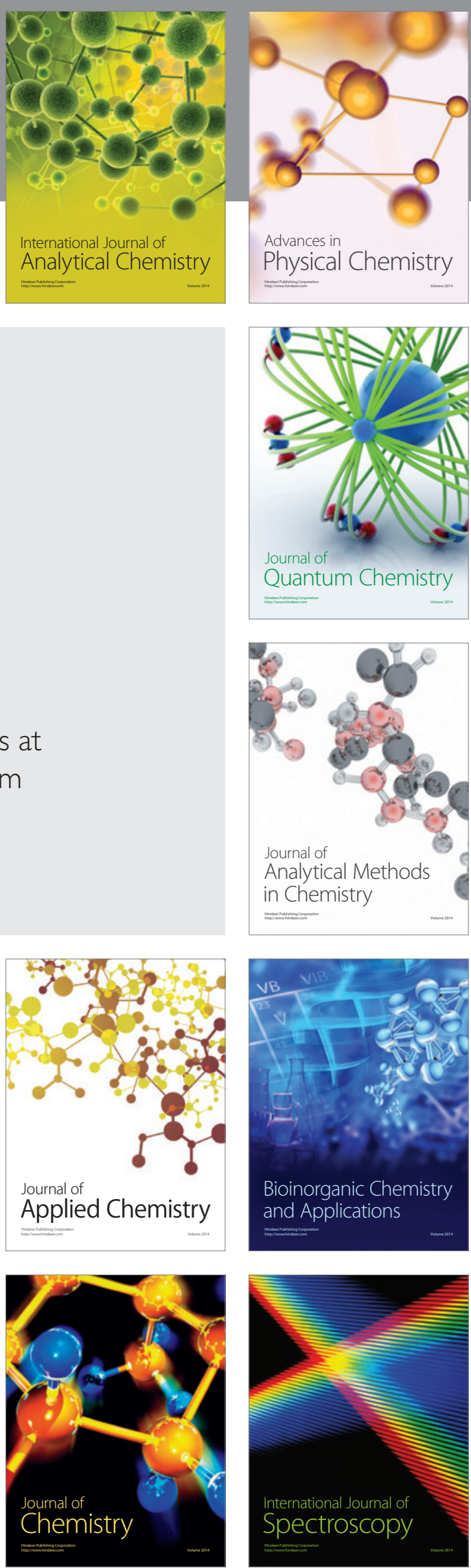